\title{
On the Possibility of a Microwave Approach for Rooms and Objects Sterilization
}

\author{
Maria Alessandra Cutolo ${ }^{1, *}$, Antimo Migliaccio², Lucia Altucci², Antonello Cutolo ${ }^{1}$, and Andrea Cusano ${ }^{3}$ \\ ${ }^{1}$ Dipartimento di Ingegneria Elettrica e delle Tecnologie per I'Informazione, Via Claudio 21, 80125 Napoli, Università di Napoli “Federico II", Italy \\ ${ }^{2}$ Dipartimento di Medicina di Precisione, Università della Campania L Vanvitelli, Via L. De Crecchio, 7 Napoli, Italy \\ ${ }^{3}$ Dipartimento di Ingegneria, Corso Garibaldi, Benevento, Italy
}

*Corresponding authors: Maria Alessandra Cutolo, Dipartimento di Ingegneria Elettrica e delle Tecnologie per I'Informazione, Via Claudio 21,80125 Napoli, Università di Napoli “Federico II”, Italy, E-mail: mariaalessandra.cutolo@unina.it

Received: 28 Jun, 2021 | Accepted: 29 Jul, 2021 | Published: 06 Aug, 2021

Citation: Cutolo MA, Migliaccio A, Altucci C, Cutolo A, Cusano A (2021) On the Possibility of a Microwave Approach for Rooms and Objects Sterilization. J Clin Case Stu 6(4): dx.doi.org/10.16966/2471-4925.230

Copyright: (c) 2021 Cutolo MA, et al. This is an open-access article distributed under the terms of the Creative Commons Attribution License, which permits unrestricted use, distribution, and reproduction in any medium, provided the original author and source are credited.

\section{Abstract}

It is well known that the heat is an enemy of both virus and microbes. Starting from this consideration we discuss the possibility of using a microwave approach for a safe and cheap sterilization of closed rooms.

Keywords: Covid; Sars-cov-2; Sterilization; Microwaves

\section{Introduction}

Hyperthermia is largely used to fight both virus and microbes in many sterilization processes and it is often exploited in some therapies against some kinds of tumors [1-23]. We have proposed a new microwave approach in order to strongly reduce the virulence of Covid 19 and related virus [22]. This can be achieved by slightly heating inner tissues up to temperatures around $40^{\circ} \mathrm{C}$ without inducing any damage to the patient tissues. When the sterilization of either objects or closed rooms is required, most of the largely used methods take advantage on strong heating (around $100^{\circ} \mathrm{C}$ ), ultra violet radiation exposition or the combined use of them. Here, we describe a new method for a quick and very cheap sterilization of closed rooms. It is based on the heating of the room through the use of a microwave beam at $2.15 \mathrm{GHz}$, which is the operating frequency of the microwave ovens. We report a description and the feasibility analysis of the proposed approach.

\section{Preliminary Remarks}

$2019-\mathrm{nCoV}$ is a new coronavirus besides the other coronavirus 229E, NL63, OC43, HKU1, Respiratory syndrome-related coronavirus (MERSr-CoV) Zhao, et al. observed that angiotensinconverting enzyme 2 (ACE2) is the receptor for SARS-CoV-2 [12]. The binding of SARS-CoV-2 on ACE2 generates an enhancement of ACE2, which induce some damages on alveolar cells. Very often, it can induce further reactions leading even to the cell death. Wang et al reported that the receptor-binding ability of SARS-CoV-2 through its specific SPIKE protein can be 10 to 20 times stronger than that of SARS-CoV [5]. In most of infectious diseases and, in particular in COVID-19, major damages arise from the violent immune reaction. On this line of argument, we have proposed the idea of exploiting hyperthermia against COVID-19 to reduce the viral load and the corresponding immune reaction. We note that the idea of using heat against Covid and other disease is not new [5-22]. In particular, radiofrequency electrical hyperthermia has been investigated [19-26]. Our idea appears suitable for its ease and low cost. We have discussed the feasibility of using microwave heating in order to reduce the virulence of the Covid and related virus [22].

In a nutshell, the critical point is represented by the working temperature, which should be high to reduce the infection, but also low enough to avoid any tissue damage. After verifying if this condition is fulfilled, a very precise temperature control of the inner tissues is required in order to avoid any negative collateral effect [1, 22-33]. Taking advantage on the strong absorption from the human tissues of the microwave radiation centered around $2.15 \mathrm{GHz}$, it seems reasonable to use this radiation to induce a well-controlled hyperthermia to decrease the virus strength.

\section{Description of the Method}

The idea of using microwave against Covid is a consequence of our efforts to find a cheap approach able, at least, to reduce the strength of the virus (together with its related effects). Even if it does not completely resolve the problem, the induced reduction of the virus strength induces the consequent reduction of the immunity reaction of the body. This, in turn, allows the use of many drugs which have been to show efficient but only at low virus levels [13-17]. We have chosen the frequency of $2.15 \mathrm{GHZ}$ because it is the working frequency of the microwave ovens, as it is strongly absorbed by the water. This mean that the technology is very well assessed, very chip and very easy to use. In addition, all the thermal parameters and physical models for biological tissues are very know when interacting with this radiation. In this paper, we analyze the feasibility of a microwave-based approach for the sterilization of closed rooms against SARS-CoV-2 virus. 
Before going on, we must observe that a temperature increase is a strong enemy of the virus and of the Covid virus as well. In particular, it has been verified that the virulence of the covid starts to rapidly decrease when the temperature increase over $40^{\circ} \mathrm{C}$ [5-16].

Many practical configurations can be realized in the shape of a single source, a linear array or a square array. The choice is a function of the right compromise between required power, area to be illuminated and cost. This possibility led us to propose this approach for a user friendly, fast, safe and cheap sterilization of object and closed rooms. Looking at the market, sterilization involves either ultraviolet radiation or the use of liquid disinfectants (eg. Alcoholic solutions, quaternary ammonium derivatives).

If we want to sterilize a closed room the simple use of the microwave bean is not enough because the absorption coefficient of the dry air is very poor and we should need very high power to increase the temperature of the room. Many different solutions can be used to solve this problem. The simplest way to increase the efficiency of the method is to increase the humidity of the environment at a level of about $50 \%$ of relative humidity as it will be clear after the discussion of a numerical example reported later in this paper. According to the previous discussion, the effective solution we propose to sterilize a closed room is the following. We propose to use a simple nebulizer which injects in the room a mixture of simple water with sterilizing liquid. Then, a small microwave source working at $2.15 \mathrm{GHz}$ (the frequency of microwave ovens) is used to heat the nebulized water and, then, all the objects or the room to be sterilized.

In order to make clear the basic principle of our idea, we discuss a numerical example. A room with a surface of $30 \mathrm{~m}^{2}$ and a height of a $3 \mathrm{~m}$ has a volume of $90 \mathrm{~m}^{3}$. In order to sterilize an environment like this about one liter of water would be needed. In SI units, cs $=1.005+1.82 \mathrm{H}$ where $1.005 \mathrm{~kJ} / \mathrm{kg}^{\circ} \mathrm{C}$ is the heat capacity of dry air, $1.82 \mathrm{~kJ} / \mathrm{kg}^{\circ} \mathrm{C}$ the heat capacity of water vapor, and $\mathrm{H}$ is the specific humidity in $\mathrm{kg}$ water vapor per kg dry air in the mixture. To bring this water at a temperature of about $60^{\circ} \mathrm{C}$ energy is needed. If the environment temperature is of about $20^{\circ} \mathrm{C}$ energy of about $40.000 \mathrm{cal}$ equivalent to about 160.000 joules should be provided. If we assume a microwave source of about 500watts (typical sources for a small microwave oven), we see that we need about 5 minutes to sterilize a room like this. The sterilization is safe because the microwave radiation is fully absorbed by the vapor and the operator is on the back of the source in a totally safe position.

We underline that the final temperature of the room depends on several factors, among which we can remind: the exact operating power of the source, the exact humidity of the room, its exact volume, the kind of furniture inside the room. All these parameters of course influence the correct exposure time required for an efficient sterilization. Indeed, the entire problem is quite simple to be solved. In fact, it is enough a thermometer in order to perform an on line and real time measurement of the temperature inside the room [2033]. This means that the correct exposure time can be easily adapted according to specific case. The temperature sensor can be a classical infrared sensor, a semiconductor sensor or an optical sensor.

\section{Conclusion and Future Trends}

We have described a new approach which can be used to construct very simple systems for a cheap and easy sterilization of a closed room. The proposed solution is based on a new microwave method for a fast and user friendly sterilization. It is based on the well assessed technology of the microwave ovens, and its basic configuration can have a cost as low as a couple of hundreds US dollars. Starting from our basic system, many different configurations (e.g. either linear or square arrays) can be easily realized according to the specific case. Now, in the very close future, we intend to perform an experimental project aimed to characterize all the performance of the proposed technique.

\section{Conflict of Interest Declaration}

By the present, we declare that no author has any conflict of interest between his scientific and institutional activities and the results discussed in the enclosed paper An innovative high frequency hyperthermia approach against SARS-CoV-2 and related virus: feasibility analysis by Maria Alessandra Cutolo, Antimo Migliaccio, Lucia Altucci, Antonello Cutolo, Andrea Cusano, which is submitted for publication on Translation Medicine Communications.

\section{References}

1. Kumar CSSR, Mohammad F (2011) Magnetic nanomaterials for hyperthermia-based therapy and controlled drug delivery. Adv Drug Deliv Rev 63: 789-808.

2. Johannsen $M$, Thiesen B, Wust $P$, Jordan A (2010) Magnetic nanoparticle hyperthermia for prostate cancer. Int J Hyperthermia 26: 790-795.

3. Hurwitz MD, Hansen JL, Prokopios-Davos S, Manola J, Wang Q, et al. (2011) Hyperthermia combined with radiation for the treatment of locally advanced prostate cancer: long-term results from DanaFarber Cancer Institute study 94-153. Cancer 117: 510-516.

4. Mahmood J, Shukla HD, Soman S, Samanta S, Singh P, et al. (2018) Immunotherapy, Radiotherapy, and Hyperthermia: A Combined Therapeutic Approach in Pancreatic Cancer Treatment. Cancers 10: 469.

5. Wang $Y$, Wang $Y$, Luo W, Huang L, Xiao J, et al. (2020) A comprehensive investigation of the mRNA and protein level of ACE2, the putative receptor of SARS-CoV-2, in human tissues and blood cells. Int J Med Sci 17: 1522-1531.

6. Ismail AM, Elfiky AA (2020) SARS-CoV-2 spike behavior in situ: a CryoEM images for a better understanding of the COVID-19 pandemic. Sig Transduct Target Ther 5.

7. Dolin R, Hirsch MS (2020) Remdesivir-An Important First Step. N Engl J Med 383: 1886-1887.

8. Cai Q, Yang M, Liu D, Chen J, Shu D, et al. (2020) Experimental Treatment with Favipiravir for COVID-19: An Open-Label Control Study. Engineering 6: 1192-1198.

9. Paggiaro AO, Carvalho VF, Gemperli R (2020) Cell Effect of different human tissue processing techniques on SARS-CoV-2 inactivationreview. Cell Tissue Bank 22: 1-10.

10. Lee YN, Chen LK, Ma HC, Yang HH, Li HP, et al. (2005) Thermal aggregation of SARS-CoV membrane protein. J Virol Methods 129: 152-161.

11. Wang $Y$, Wu X, Wang $Y, L i B$, Zhou H, et al. (2004) Low stability of nucleocapsid protein in SARS virus. Biochemistry 43: 11103-11108.

12. Ma Y, Zhao Y, Liu J, He X, Wang B, et al. (2020) Effects of temperature variation and humidity on the death of COVID-19 in Wuhan, China. Sci Total Environ 724: 138226.

13. Briz-Redón A, Serrano-Aroca A (2020) A spatio-temporal analysis for exploring the effect of temperature on COVID-19 early evolution in Spain. Sci Total Environ 728: 138811.

14. Leung C (2020) Risk factors for predicting mortality in elderly patients with COVID-19: A review of clinical data in China. Mech Ageing Dev 188: 111255. 
15. Dewhirst MW, Viglianti BL, Lora-Michiels $\mathrm{M}$, Hanson $\mathrm{M}$, Hoopes PJ (2003) Basic principles of thermal dosimetry and thermal thresholds for tissue damage from hyperthermia. Int J Hyperthermia 19: 267294.

16. Lassche G, Frenzel T, Mignot MH, Jonker MA, van der Hoeven JG, et al. (2020) Thermal distribution, physiological effects and toxicities of extracorporeally induced whole-body hyperthermia in a pig model. Physiol Rep 8: e14366.

17. Mahmoudi K, Bouras A, Bozec D, Ivkov R, Hadjipanayis C (2018) Magnetic hyperthermia therapy for the treatment of glioblastoma: a review of the therapy's history, efficacy and application in humans. Int J Hyperthermia 34: 1316-1328.

18. Lee SY, Lee NR, Cho DH, Kim JS (2017) Treatment outcome analysis of chemotherapy combined with modulated electro-hyperthermia compared with chemotherapy alone for recurrent cervical cancer, following irradiation. Oncol Lett 14: 73-78.

19. Andocs G, Rehman MU, Zhao QL, Tabuchi Y, Kanamori M, et al. (2016) Comparison of biological effects of modulated electro-hyperthermia and conventional heat treatment in human lymphoma U937 cells. Cell Death Discov 2: 16039.

20. Principe S, Giaquinto M, Micco A, Cutolo MA, Riccio M, et al. (2020) Thermo-plasmonic lab-on-fiber optrodes. Optics Laser Technol 132: 106502.

21. Vancsik T, Kovago C, Kiss E, Papp E, Forika G, et al. (2018) Modulated electro-hyperthermia induced loco-regional and systemic tumor destruction in colorectal cancer allografts. J Cancer 9: 41-53.

22. Cutolo MA, Migliaccio A, Altucci L, Cutolo A, Cusano A (2021) An innovative high frequency hyperthermia approach against SARSCoV-2 and related virus: feasibility analysis. Archives Clin Biomed Res 5: 569-580.
23. Fisher DT, Chen Q, Skitzki JJ, Muhitch JB, Zhou L, et al. (2011) IL-6 trans-signaling licenses mouse and human tumor microvascular gateways for trafficking of cytotoxic T cells. J Clin. Invest 121: 38463859 .

24. V'kovski P, Gultom M, Kelly JN, Steiner S, Russeil J, et al. (2021) Disparate temperature-dependent virus-host dynamics for SARSCoV-2 and SARS-CoV in the human respiratory epithelium. PLoS Biol 19: e3001158.

25. Rébé C, Ghiringhelli F, Garrido C (2021) Can the hyperthermiamediated heat shock factor/heat shock protein 70 pathway dampen the cytokine storm during SARS-CoV-2 infection? Br J Pharmacol.

26. Herder V, Dee K, Wojtus JK, Goldfarb D, Rozario C, et al. (2020) Elevated temperature inhibits SARS-CoV-2 replication in respiratory epithelium independently of the induction of IFN-mediated innate immune defences. bioRxiv.

27. Belon L, Skidmore P, Mehra R, Walter E (2021) Effect of a fever in viral infections-the 'Goldilocks' phenomenon? World J Clin Cases 9: 296-307.

28. Mancilla-Galindo J, Galindo-Sevilla N (2021) Exploring the rationale for thermotherapy in COVID-19. Int J Hyperthermia 38: 202-212.

29. Righini GC, Tajani A, Cutolo A (2009) An Introduction to Optoelectronic Sensors. World Scientific Publishing Co.

30. Cusano A, Cutolo A, Arregui FJ, Giordano M (2012) Optochemical Nanosensors. Taylor \& Francis.

31. Giaquinto M, Ricciardi A, Cutolo A, Cusano A (2018) Lab-on-Fiber Plasmonic Probes for Ultrasound Detection: A Comparative Study. J Lightwave Technol 34: 5189-5198. 